\title{
SIR JOHN HERBERT PARSONS
}

\author{
An appreciation \\ BY \\ Professor J. VAN DER HOEve
}

SIR JOHN HERBERT PARSONS reaches the age of 80 years on September 3rd of this year. His whole life has been devoted to his and our beloved profession; ophthalmology in England is greatly the gainer for his work and his reputation is truly international.

His writings on all aspects of ophthalmology are numerous and well known; and in addition to his professional activities, he served his country, both in war and in public life in peace, in many capacities. For these services many honours were accorded to him. My tribute to him, however, is essentially concerned with the work he has done for the International Council of Ophthalmology, a sphere wherein we worked together and where I knew him best. After the first World War an Anglo-American Convention of Ophthalmology was held in 1925 when a Committee for reviving the International Congresses was nominated. The English members of the Committee were Treacher Collins, Sir John Parsons and Leslie Paton. As a result a meeting was held at Scheveningen in 1927, where there gathered 50 oculists from 25 different nations, and here the plans were laid for the Congress of 1929. It is interesting that we met again afterwards in the same year (1927) when we each received the degree of L1.D. at Edinburgh.

In the name of the oculists who serve on the International Council of Ophthalmology, I wish from the very bottom of my heart that Sir John will still have many more years of good health and happiness. 